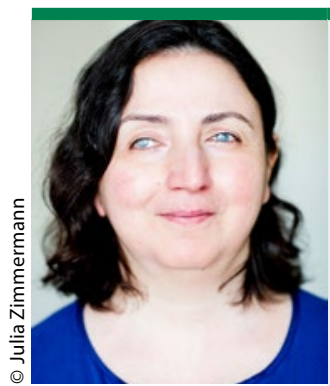

Filiz Demir

Seit 2014 festangestellte MTU bei "Discovering Hands ${ }^{\oplus u}$

\title{
Nachgefragt
}

\section{„Beim Small-Talk kann ich viele Fragen beantworten!"}

Filiz Demir, 2010 erblindet, arbeitet seit 2014 als MTU für "Discovering Hands ${ }^{\circledR}$. Hier berichtet sie über ihre Erfahrungen.

? Frau Demir, wie viele Frauen untersuchen Sie täglich und wie gehen Sie dabei vor?

Filiz Demir: Im Schnitt taste ich täglich sechs Frauen ab. Die Untersuchung wird nach einem festen Standard durchgeführt, den ich in meiner Ausbildung gelernt habe. Zuerst wird die Anamnese erhoben. Dann taste ich die Lymphknoten am Hals, ober- und unterhalb des Schlüsselbeins und in den Achselhöhlen ab; das erfolgt im Sitzen. Danach legt sich die Patientin auf den Rücken und ich beklebe den Oberkörper mit den sogenannten Doku-Streifen: Einer kommt längs auf das Brustbein, zwei längs über die Brust und zwei unter den Arm, sodass jede Brust in zwei Zonen geteilt wird. Auf den Streifen befinden sich taktile Markierungen. Nach geeigneter Lagerung taste ich mich von Reihe zu Reihe vor, das heißt, wenn ich bei der Markierung mit den vier Punkten beginne, muss ich auf der anderen Seite bei der entsprechenden Markierung ankommen.

? Kommen Sie dabei mit der Patientin ins Gespräch? Demir: Ja, natürlich. Wir unterhalten uns immer, sodass die Patientin die Möglichkeit hat, Fragen zu stellen. Beim Small-Talk kommen oft Fragen auf, die sich die Patientin dem Arzt nicht unbedingt zu stellen getraut hätte. Manchmal kann ich auch Missverständnisse aufklären: Zum Beispiel denken viele Frauen, wenn sie sich an der Brust gestoßen haben, könnte daraus Krebs entstehen. Es werden auch viele Fragen zur Mammografie gestellt. Hier kann ich ihnen die Vor- und Nachteile aufzeigen; das wurde uns in der Ausbildung vermittelt. Wir sprechen von den drei Säulen der Brustkrebsfrüherkennung, einmal das gründliche Tasten, dann der Ultraschall und die Mammografie. Ich sage den Frauen immer, dass sich diese Untersuchungen ergänzen und meine Untersuchung die Mammografie nicht ersetzt.
? Wie erfahren die Patientinnen von „discovering hands"?

Demir: Unterschiedlich. Die Patientinnen in unserer Praxis werden natürlich darüber aufgeklärt. Viele erfahren es aber auch über Mundpropaganda, andere haben darüber gelesen oder einen Bericht gehört. Ich untersuche viele Patientinnen, die gar nicht regulär bei uns in Behandlung sind.

? Kommt es vor, dass Patientinnen Ihnen gegenüber erst mal verunsichert sind?

Demir: Das kommt immer wieder vor. Aber dadurch, dass ich Zeit habe, können sie diese Unsicherheit während der Untersuchung ablegen. Ich merke das immer daran, wenn jemand ganz still ist und gar keine Fragen stellt ...

? Was haben Sie bei der Tastuntersuchung dem Arzt voraus?

Demir: Ich glaube, es ist die Kombination aus dem gut ausgeprägten Tastsinn und der standardisierten Untersuchungsmethode, bei der ich mich wirklich Zentimeter für Zentimeter vortaste. Ich mache das ja jeden Tag. Dabei entwickelt man ein Gespür dafür, was sich anders anfühlt und wo nochmal nachgeschaut werden muss.

? Wie reagieren Sie, wenn Sie etwas gefunden haben?

Demir: Ich sage der Patientin, dass ich eine Struktur getastet habe. Dass das nichts Schlimmes sein muss und ich jetzt den Arzt dazu hole, der dann nochmal mit dem Ultraschall nachgucken kann.

? Haben Sie schon einmal eine Struktur getastet, die sich als bösartig herausgestell hat?

Demir: Ja, das kommt regelmäßig vor, zuletzt vor zwei Monaten: Das hat sich schon vom Tasten her komisch angefühlt, anders als sonst. Der Tumor konnte vollständig entfernt werden, die Lymphknoten waren noch nicht betroffen. Die Dame brauchte auch keine Chemotherapie. nach geeigneten Untersucherinnen gewandt hatte, konnten ihn jedoch überzeugen, daraus ein gemeinnütziges Vorhaben zu entwickeln. Ein Finanzier fand sich zunächst im Landschaftsverband Rheinland; für das Projektkonsortium konnte u. a. auch die Ärztekammer Nordrhein gewonnen werden.
2011 gründete Hoffmann die gemeinnützige Organisation „discovering hands “".

In einem zertifizierten neunmonatigen Curriculum bildet die Organisation blinde Frauen zur „Medizinischen Tastuntersucherin“ (MTU) aus. Bundesweit sind inzwischen 28 entsprechend qualifi- 